\title{
Ensino Médico e Extensão em Áreas Ribeirinhas da Amazônia
}

\section{Medical Teaching and Community Outreach in Amazonian Riverside Areas}

\author{
Antonio Camargo Martins ${ }^{I}$ \\ Andrews Roberto Schlosser \\ Rayanne Alves de Arruda \\ Wagner Werner Klein ${ }^{I}$ \\ Breno Wilson Benevides Andradel \\ Andre Luis Bezerra Labat ${ }^{I}$ \\ Mardelson Nery de Souzal \\ Mônica da Silva-Nunes ${ }^{I}$
}

PALAVRAS-CHAVE:

- Educação Médica

- Ensino;

- Extensão;

- Medicina Tropical.

\section{KEYWORDS:}

- Medical Education;

- Teaching;

- Community-Institutional Relations;

- Tropical Medicine.

Recebido em: 01/02/2013

Reencaminhado em: 14/06/2013

Aprovado em: 28/08/2013

\section{RESUMO}

O ensino médico há alguns anos vem passando por uma transição do modelo clássico teórico para abordagens práticas e baseadas em problemas. Fundamentando-se em uma abordagem prática ambulatorial, criou-se um projeto de extensão para o ensino simultâneo a alunos de diferentes anos do curso médico com uma população ribeirinha, em que cada acadêmico utilizou suas habilidades adquiridas no curso para a criação de um serviço ambulatorial (acolhimento, pré-consulta, consulta médica, vacinação e dispensação de medicamentos), de forma a promover um serviço de saúde. Esta ação ocorreu em áreas remotas da Amazônia brasileira, mostrando que é possível unir extensão e ensino na formação de médicos mais conscientes das diferentes realidades socioeconômicas e culturais brasileiras.

\begin{abstract}
The model of medical education has been undergoing a transition between classical theory and problem-oriented teaching based in the past years. Relying on an outpatient practice, we created an outreach project for the simultaneous teaching of students from different years of the medical course integrated with the consultation of a riverside population, where each used their academic skills already acquired in the course to create an outpatient service (pre-consultation, medical consultation, vaccination and drug dispensing) in order to promote a health service. This action occurred in the most remote areas of the Brazilian Amazon, showing that it is possible to combine community outreach projects and teaching while making future medical doctors more aware of the different Brazilian socioeconomic and cultural realities.
\end{abstract}




\section{INTRODUÇÃO}

Os cursos de Medicina localizados em universidades públicas da Amazônia enfrentam várias dificuldades, entre elas a falta de hospitais universitários, a escassez de docentes em algumas especialidades médicas, a ausência de procedimentos médicos mais complexos na rotina dos hospitais conveniados e a falta de infraestrutura geral. Essa realidade pode ser constatada na mídia comum, com base em entrevistas e relatos de manifestações discentes em prol de melhorias no ensino ${ }^{1}$.

Além das dificuldades descritas acima, a região amazônica apresenta uma realidade social muito diferente da de outras regiões, que se reflete na saúde de sua população de modo particular. Por exemplo, o acesso a frutas e legumes frescos é quase inexistente em algumas localidades, resultando em alta prevalência de anemias carenciais. A alta umidade da região favorece dermatites específicas, como dermatofitoses, pitiríase versicolor, piedras e algumas relacionadas diretamente a avitaminoses, como a pelagra. O deslocamento dos moradores das regiões rurais e ribeirinhas para áreas urbanas é caro e demorado, o que restringe o acesso dessa população aos serviços de saúde básicos, como vacinação, pré-natal, puericultura, tratamento odontológico e acompanhamento de hipertensão e diabetes. Por fim, o próprio ambiente da floresta leva ao aparecimento de doenças tropicais de alta prevalência, como malária, leishmaniose, hepatites virais, hidatidose, lacaziose, hanseníase e acidentes ofídicos.

As novas metodologias empregadas nos cursos de graduação enfatizam o aprendizado durante a prática, com maior integração dos alunos com os serviços de saúde². Dos 17 cursos de Medicina localizados na região amazônica, $83,23 \%$ (15) estão nas capitais ou cidades com mais de 100 mil habitantes, ou seja, em áreas urbanas consolidadas ${ }^{3}$. Portanto, mesmo adotando técnicas de ensino modernas, o contato dos alunos com as peculiaridades do atendimento em saúde na Amazônia pode não ser completo. Tomando como exemplo o Acre, onde há um único curso de Medicina no Estado inteiro, localizado na capital, os alunos, mesmo cursando graduação na Amazônia, têm pouco contato com doenças como malária, lacaziose, hanseníase e com a realidade social de populações nativas, como seringueiros, indígenas, assentados rurais e população nativa ribeirinha. Quando esses alunos se formam e assumem empregos no interior da Amazônia, ainda estão despreparados para assumir completamente sua função e lidar com as dificuldades de trabalhar no interior, como a ausência de exames diagnósticos, a baixa instrução da população, a dificuldade de compreender uma prescrição médica e os hábitos de vida diferentes, como só comer carne de caça ou pesca ou fazer uma única refeição por dia.

Essas deficiências podem ser sanadas em parte com estágios fora dos grandes núcleos urbanos, o que requer uma infraestrutura razoável por parte da instituição de ensino. Mas, mesmo assim, são raros os cursos na Amazônia que oferecem estágios em áreas ribeirinhas, seringais e aldeias indígenas, pelos custos de locomoção e condições de permanência na área. O fato de o Ministério da Saúde disponibilizar unidades básicas de saúde em áreas ribeirinhas possibilita uma primeira infraestrutura para esse tipo de aprendizado.

Para os moradores da região amazônica, o contato com médicos que vêm de outra realidade cultural (geralmente recém-formados de Estados extra-amazônicos) pode também representar uma barreira. Em primeiro lugar, a linguagem do matuto ou amazônica pode ser desconhecida e de difícil interpretação pelo médico (por exemplo, "provocar", na linguagem amazônica, significa ter náuseas), e o paciente pode se sentir incompreendido. Soma-se a isso o fato de que o médico, muitas vezes, desconhece a realidade cultural em que está se inserindo e não possui ainda certas habilidades verbais (no caso, o linguajar da região) e não verbais (modos de conduta apropriados ao grupo cultural a ser atendido, como, por exemplo, apertar firmemente a mão calejada e suja do agricultor, aceitar o café ou suco na visita domiciliar como forma de diminuir a distância social em relação às famílias mais pobres e outras atitudes moderadoras da pluralidade cultural $)^{4}$.

Neste artigo relatamos uma experiência de ensino na região amazônica vinculada a uma atividade de extensão financiada pela própria instituição de ensino superior com parceria com órgãos de saúde municipais. A característica principal deste projeto foi proporcionar o contato dos alunos de Medicina conforme sua experiência prévia acumulada com uma população ribeirinha extremamente carente e que não recebia atendimento médico havia cinco anos.

\section{Características da localidade e da população}

$\mathrm{O}$ projeto foi conduzido em áreas ribeirinhas do município de Mâncio Lima, no Acre (Figura 1), situado próximo ao extremo oeste do País. Foram visitadas três localidades do Rio Azul, afluente do Rio Moa: Bom Sossego, Nova Lição e Três Unidos. 
Figura 1

Localização da bacia amazônica, do estado do Acre e do Rio Azul (local da ação de extensão)

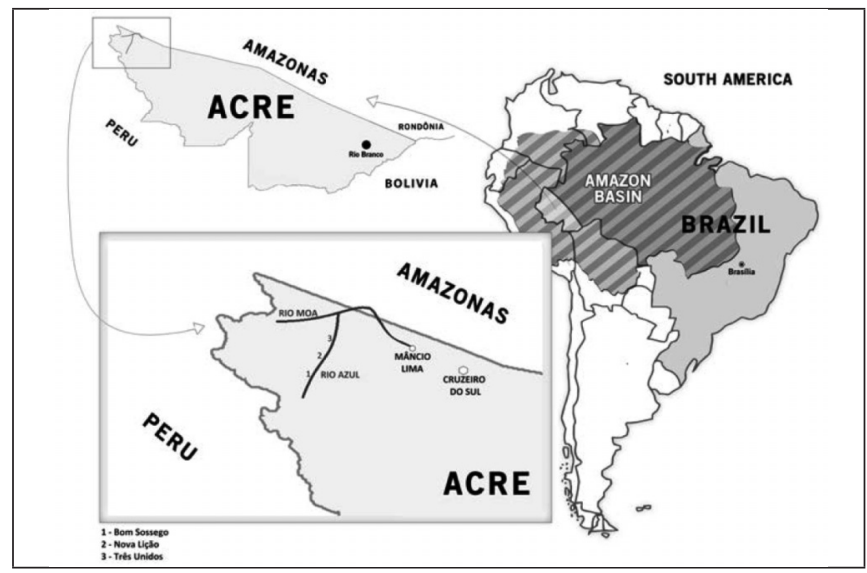

A população em cada localidade gira entre 100 e 150 pessoas, incluindo desde recém-nascidos até idosos, com predomínio de adultos jovens. A base alimentar da população é carne de caça, peixe e farinha de mandioca, sendo raro encontrar cultivos de hortaliças e criação de animais para abate. A água usada para beber e na preparação de alimentos é retirada do rio e de cacimbas (buracos escavados no chão, de onde brota água espontaneamente) e comumente não passa por nenhum tratamento, como fervura ou uso de hipoclorito.

As necessidades fisiológicas são feitas na mata ou em "casinhas" (fossa). O banho pessoal e a lavagem de roupa e de utensílios de cozinha são feitos no rio ou em cacimbas.

Não há médicos, dentistas ou enfermeiros na região ribeirinha, sendo o acesso à saúde totalmente dependente da zona urbana do município de Mâncio Lima. Quanto à educação infantojuvenil e alfabetização de adultos, são realizadas em escolas rurais com salas unificadas, ou seja, várias séries em uma mesma sala de aula. As crianças e os adultos chegam à escola por meio do barco escolar, que os busca e deixa em casa a cada dia de aula.

A renda local é proveniente da venda de farinha de mandioca ou de atividades extrativistas (banana, açaí e buriti), sendo caça, pesca e plantio de mandioca a base da subsistência desse grupo.

Em estudo prévio realizado na zona urbana do município em 2012, com 1.287 indivíduos, a mediana de renda do chefe da família foi de $\mathrm{R} \$ 600,00$ (dados ainda não publicados). Não temos informação sobre a renda média mensal da área ribeirinha, mas ela deve girar em torno de R\$200,00 a R\$300,00, sendo nítido que quase a totalidade da população vive entre a pobreza e a miséria. O gasto que um indivíduo dessas localidades tem com combustível para se deslocar de sua casa até a área urbana de Mâncio Lima é calculado em cerca de R\$ 200,00, dificultando o acesso, que só é feito em casos de urgência ou extrema necessidade.

\section{Itinerário do projeto}

Para promover o atendimento nas localidades ribeirinhas, foi realizada uma parceria entre a Secretaria Municipal de Saúde de Mâncio Lima, a Gerência de Controle de Endemias e a Universidade Federal do Acre (Ufac). A equipe da Ufac ficou responsável pelo atendimento médico, e a Secretaria de Saúde e Controle de Endemias pela parte logística, como disponibilizar barcos, guias, localidades para passar a noite e medicamentos.

A viagem foi programada para ser realizada em cinco dias, nas três localidades diferentes, sendo tanto o atendimento quanto a hospedagem efetuados nas escolas rurais locais. $\mathrm{O}$ acesso até as localidades foi feito utilizando-se três barcos de pequeno porte com motores de baixa potência, totalizando 12 horas de viagem até a localidade mais distante.

Participaram do atendimento sete acadêmicos de Medicina (um do quarto ano, um do terceiro ano, três do segundo ano e dois do primeiro ano, selecionados entre 40 acadêmicos interessados em participar do projeto), um médico com experiência em Medicina Tropical e Epidemiologia e uma auxiliar de enfermagem responsável pela vacinação, além de três barqueiros responsáveis pela locomoção da equipe.

\section{Metodologia do atendimento}

$\mathrm{O}$ atendimento à população ribeirinha consistiu em verificação de pressão arterial sistêmica, pré-consulta, consulta médica, vacinação e dispensação de medicamentos. A consulta médica foi efetuada pela médica coordenadora da atividade. Os acadêmicos foram distribuídos nessas atividades conforme as disciplinas já cursadas durante a graduação ou segundo disciplinas que seriam cursadas no semestre seguinte, da seguinte forma: os acadêmicos do quarto e terceiro anos, que já haviam cursado Semiologia, ficaram responsáveis pela pré-consulta, em que foi efetuada a anamnese e o exame físico. $\mathrm{O}$ acadêmico do quarto ano, por estar cursando a disciplina de Clínica Médica, também ficou responsável por elaborar hipóteses diagnósticas e, em alguns casos, a conduta. Em seguida, o paciente era visto pelo médico da equipe, que revisava a anamnese e o exame físico, elaborava a hipótese diagnóstica e estabelecia a con- 
duta a ser tomada. Os alunos do primeiro e segundo anos foram distribuídos entre as seguintes funções: acolhimento dos pacientes, dispensação de medicamentos segundo a prescrição médica, acompanhamento da consulta médica e da pré-consulta e aferição da pressão arterial, havendo rodízio entre esses alunos nessas cinco funções. Além disso, os alunos também acompanharam a vacinação efetuada pela auxiliar de enfermagem.

Essa distribuição foi feita levando-se em conta o fato de os discentes do primeiro ano estarem cursando disciplinas gerais de Medicina da Família, em que já entraram em contato com a parte organizacional de um serviço de saúde e verificação de pressão arterial sistêmica, e os alunos do segundo ano terem cursado Microbiologia Médica e Parasitologia, em que aprenderam, além dos princípios de doenças infecciosas, rudimentos de antibioticoterapia, sendo interessante para eles exercitar esses conhecimentos na farmácia gerada no atendimento.

Ao final do atendimento em cada localidade, as fichas de atendimento eram discutidas com todos os alunos, e em alguns casos os alunos do terceiro e quarto anos eram chamados para efetuar o exame físico junto com o médico da equipe durante o próprio atendimento, permitindo a checagem do seu exame físico e correções de dúvidas em tempo real.

Dessa forma, todos os alunos tiveram contato com anamnese, exame físico, hipótese diagnóstica, conduta e dispensação de medicamentos, executando funções conforme as habilidades já adquiridas durante o ensino médico e observando atividades que virão a aprender durante a graduação. Essa metodologia permitiu que todos aprendessem na prática a importância e o raciocínio por trás de cada um desses atos.

\section{Resultados do atendimento}

$\mathrm{O}$ atendimento foi realizado em três localidades diferentes, sendo iniciado na mais distante, denominada Bom Sossego (localidade 1, 51 consultas), no primeiro dia de atendimento. No segundo e terceiro dias, os atendimentos foram efetuados na comunidade Nova Lição (localidade 2, 43 consultas) e Três Unidos (localidade 3, 51 consultas), respectivamente. A relação entre número de atendimentos e idade por localidade está apresentada na Tabela 1. As morbidades dessa população foram estratificadas em dez categorias, as menos frequentes agrupadas em "outras morbidades", e os pacientes que se consultavam para receber orientação sobre saúde foram agrupados em "sem queixas" (Tabela 2).
TABELA 1

Relação entre número de atendimentos e idade por localidade

\begin{tabular}{|c|c|c|c|c|}
\hline & $\begin{array}{c}\text { Localidade } \\
1\end{array}$ & $\begin{array}{l}\text { Localidade } \\
2\end{array}$ & $\begin{array}{c}\text { Localidade } \\
3\end{array}$ & $\begin{array}{c}\text { Todas as } \\
\text { localidades }\end{array}$ \\
\hline \multicolumn{5}{|l|}{ Sexo masculino } \\
\hline $\begin{array}{l}\text { Número de } \\
\text { indivíduos }\end{array}$ & 19 & 18 & 21 & 58 \\
\hline Média de idade & 26 & 26 & 17 & 23 \\
\hline Mediana de idade & 16 & 18 & 7 & 15 \\
\hline Mínimo - máximo & $3-74$ & $2-69$ & $1-75$ & $1-75$ \\
\hline \multicolumn{5}{|l|}{ Sexo feminino } \\
\hline $\begin{array}{l}\text { Número de } \\
\text { indivíduos }\end{array}$ & 32 & 25 & 30 & 87 \\
\hline Média de idade & 32 & 26 & 24 & 27 \\
\hline Mediana de idade & 25 & 27 & 28 & 26 \\
\hline Mínimo - máximo & $0-79$ & $0-75$ & $5-42$ & $0-79$ \\
\hline \multicolumn{5}{|l|}{ Ambos os sexos } \\
\hline $\begin{array}{l}\text { Número de } \\
\text { indivíduos }\end{array}$ & 51 & 43 & 51 & 145 \\
\hline Média de idade & 29 & 26 & 19 & 25 \\
\hline Mediana de idade & 23 & 19 & 16 & 22 \\
\hline Mínimo - máximo & $0-79$ & $0-75$ & $1-75$ & $0-79$ \\
\hline
\end{tabular}

Média de idade, mediana de idade e mínimo-máximo são expressos em anos.

TABELA 2

Estratificação das morbidades por localidade

\begin{tabular}{|c|c|c|c|c|}
\hline Morbidade & $\begin{array}{c}\text { Localidade } \\
1 \\
\text { N }(\%) \\
\end{array}$ & $\begin{array}{c}\text { Localidade } \\
2 \\
\mathrm{~N}(\%) \\
\end{array}$ & $\begin{array}{c}\text { Localidade } \\
3 \\
\mathrm{~N}(\%) \\
\end{array}$ & $\begin{array}{c}\text { Total } \\
\text { N (\%) }\end{array}$ \\
\hline Lombalgia & $5(9,8)$ & $11(25,6)$ & $13(25,5)$ & $29(20,0)$ \\
\hline Micoses & $8(15,7)$ & $5(11,6)$ & $8(15,7)$ & $21(14,5)$ \\
\hline Infecção respiratória & $6(11,8)$ & $8(18,6)$ & $6(11,8)$ & $20(13,8)$ \\
\hline Gastroenterite aguda & $4(7,8)$ & $5(11,6)$ & $1(2,0)$ & $10(6,9)$ \\
\hline Verminose & $3(5,9)$ & $3(7,0)$ & $4(7,8)$ & $10(6,9)$ \\
\hline Queixa ginecológica & $3(5,9)$ & $2(4,7)$ & $4(7,8)$ & $9(6,2)$ \\
\hline Otite média aguda & $1(2,0)$ & $2(4,7)$ & $4(7,8)$ & $7(4,8)$ \\
\hline $\begin{array}{l}\text { Infecção do trato } \\
\text { urinário }\end{array}$ & $2(3,9)$ & $2(4,7)$ & $3(5,9)$ & $7(4,8)$ \\
\hline $\begin{array}{l}\text { Queixa de } \\
\text { odontologia }\end{array}$ & $1(2,0)$ & $3(7,0)$ & $2(3,9)$ & $6(4,1)$ \\
\hline Sem queixas & $2(5,9)$ & $0(0)$ & $0(0)$ & $2(2,1)$ \\
\hline Outras morbidades & $15(29,4)$ & $6(14,0)$ & $11(21,6)$ & $32(22,1)$ \\
\hline Total de queixas & 48 & 47 & 56 & 141 \\
\hline $\begin{array}{l}\text { Número } \\
\text { atendime }\end{array}$ & $51(35,2)$ & $43(29,6)$ & $51(35,2)$ & 145 \\
\hline
\end{tabular}


Na primeira localidade, o atendimento correspondeu às pessoas com idade mais elevada em relação às outras duas comunidades (média de idade de 29 anos e mediana de 23 anos), sendo as morbidades mais prevalentes nessa área as micoses de pele (tinha, dermatofitose, pitiríase versicolor), seguidas das infecções respiratórias agudas.

A principal característica dessa localidade foi o baixo índice socioeconômico, evidenciado pela grande quantidade de pacientes que relatavam epigastralgia por fazerem apenas uma refeição por dia, por não terem alimentos suficientes em casa.

Na segunda localidade, os pacientes apresentavam idade intermediária entres as outras duas áreas (média de idade de 26 anos e mediana de 19). As morbidades mais prevalentes foram a lombalgia, seguida de infecções respiratórias agudas, micoses e gastroenterites agudas. Nessa localidade, além de pacientes de baixo risco, os alunos se depararam com pacientes graves que necessitavam de atendimento hospitalar, como uma criança de dois anos com pneumonia e todos os seus sinais de gravidade. Devido à elevada prevalência de infecções respiratórias agudas, foi possível aos alunos observar as diferenças clínicas das infecções respiratórias leves e graves, dentre elas gripe, bronquiolite e pneumonias grave e não grave.

$\mathrm{Na}$ terceira localidade, o atendimento caracterizou-se principalmente pela consulta pediátrica de escolares e pré-escolares. Em relação às morbidades, as mais prevalentes foram: lombalgia, micoses, infecções respiratórias, verminose e otite média aguda. Os alunos puderam observar vários casos de otite média aguda, alguns deles com supuração e outros em estágio crônico, percebendo a relação entre o contato com o meio ambiente, a desnutrição e a falta de acesso médico. Dentre os casos mais graves nessa localidade, podemos destacar um garoto de cinco anos com história de perda da audição, otorreia e otalgia havia um mês, cuja otoscopia não pôde ser realizada pela grande quantidade de pus presente, mostrando como a dificuldade do deslocamento até a zona urbana e a falta de atendimento local têm grande impacto na saúde dos moradores. Nessa comunidade, alguns encaminhamentos foram feitos para o serviço médico urbano, mas a capacidade de deslocamento dos pacientes era mínima por conta das condições socioeconômicas, o que acaba tornando os encaminhamentos sem resolutividade.

Nas três localidades, chamou a atenção a frequência de lombalgia e de acidentes de trabalho tanto em homens quanto em mulheres, demonstrando a relação entre saúde e condições de trabalho. Por outro lado, o número de pacientes que referia diabetes e hipertensão arterial era mínimo, mostrando os aspectos saudáveis da vida ribeirinha e, portanto, uma realidade muito diferente da encontrada na área urbana.

\section{Experiência}

Um dos fatores mais interessantes do projeto é a inclusão dos alunos no modo de vida da população ribeirinha nos aspectos básicos do dia a dia, uma vez que a equipe foi hospedada na própria área ribeirinha. Isto permitiu melhor entendimento da realidade social e cultural local e de seus reflexos na saúde.

Os acadêmicos passaram cinco dias vivendo como ribeirinhos, sem energia elétrica ou gerador, não tendo acesso a redes de celular ou internet, tendo que usar lanternas, lamparinas ou velas. Todas as noites eles presenciavam aspectos interessantes da cultura da Amazônia, como a crença em seres mitológicos que protegem a mata e os rios, transmitidos por lendas, como a da mãe da mata e da mãe d'água, seres que protegem a floresta e o rio e equilibram a relação entre o ribeirinho e a floresta.

As condições de hospedagem incluíram dormir em redes, usar mosquiteiros, usar fossas e tomar banho no rio ou em cacimbas, além do contato com a fauna e a flora locais. Isto permitiu aos alunos verificar as condições epidemiológicas em que ocorre a transmissão de parasitoses intestinais, malária e doenças bacterianas, como a otite média aguda, por exemplo. As refeições foram feitas com água do rio, usando alimentos não perecíveis, carne de caça ou peixe, bem como farinha de mandioca. Com isso, os discentes presenciaram as condições de alimentação da população ribeirinha e suas consequências para a saúde, como a falta de verduras, legumes e frutas, bem como as vantagens, como o baixo consumo de sal e açúcar. Além disso, o contato com o ciclo chuva-sol da floresta, com dias intensamente quentes e abafados e noites frias, e o contato com a água do rio permitiram aos alunos entender a alta prevalência de micoses superficiais e queixas ginecológicas.

\section{DISCUSSÃO}

A realização de ações de ensino e extensão como a relatada em áreas isoladas da Amazônia beneficia tanto a população atendida como os alunos, permitindo o acesso ao atendimento e ao tratamento médico gratuito a uma população negligenciada e promovendo uma forma distinta de aprendizagem aos alunos.

No caso desta experiência, a aprendizagem teve dois diferenciais importantes. Em primeiro lugar, a atividade de ensino foi efetuada com uma população caracteristicamente amazônica, que é a população ribeirinha. Considerando que a prática médica na Amazônia inclui o atendimento de populações especiais (ribeirinhos, indígenas e assentados rurais) e que durante o curso médico da Universidade Federal do Acre os alunos não entram em contato formalmente com essas populações, esse modelo de projeto de extensão permite preencher essa lacuna, pelo menos em parte. No Estado do Acre, 
por exemplo, os empregos médicos nas cidades do interior envolvem contato com populações indígenas, populações rurais ou ribeirinhas, além da população urbana a que os alunos estão acostumados. O modelo dessa ação de ensino e extensão possibilita uma forma de aprendizagem médica ambulatorial vinculada à realidade epidemiológica das comunidades especiais. Como exemplo importante, temos a alta prevalência de otites médias agudas na população ribeirinha, sendo que os acadêmicos puderam examinar sete casos diferentes em apenas três dias, experiência compartilhada pelos demais acadêmicos da equipe. O segundo diferencial foi a distribuição dos acadêmicos conforme as habilidades técnicas já adquiridas durante o curso de graduação e a estruturação de um serviço ambulatorial com acolhimento, atendimento médico, vacinação e farmácia em uma área remota e sob supervisão médica. Com isso, os discentes obtiveram a visão de como construir um serviço que atenda às necessidades da população por meio do esforço e trabalho em equipe.

Dornan e Bundy ${ }^{2}$ apresentaram evidências de que a introdução da prática precoce (early practice) no curso de Medicina traz vantagens, como facilitar a transição para os estágios clínicos, dar uma orientação social ao contexto do curso, motivar os alunos e aumentar sua percepção de si mesmos, dos seus objetivos e dos pacientes, ao mesmo tempo em que os torna mais confiantes e seguros, além de inserir o contexto teórico do curso na prática médica e de outras profissões. Portanto, ações de ensino como a veiculada neste projeto de extensão são importantes para a inserção do aluno no contexto médico e social do curso desde o início da sua formação e também constituem atividades motivadoras que aumentam o interesse pelas matérias teóricas ${ }^{5}$.

O ganho humanístico na formação desses profissionais é nítido, transportando a empatia do jovem e a sede de conhecimento para uma atividade prática, entendendo que o modo peculiar de vida dessas pessoas e sua localização geográfica impossibilitam uma série de atitudes simples relacionadas à saúde no dia a dia.

Esta experiência também serviu para construir um atendimento e um entendimento plurais, bem como propiciar aos profissionais envolvidos a oportunidade de adquirir competências não verbais e capacidade de reconhecer as diferenças culturais ${ }^{4}$. Em outras palavras, as atividades desenvolvidas propiciaram a troca cultural entre a equipe de saúde e os pacientes. Em alguns casos, houve necessidade de explicar o processo saúde-doença aos pacientes consultados, verificando, assim, as concepções de cada um dos atendidos e reconhecendo as diferenças na percepção médica e do paciente. Ao fazer a dispensação de medicamentos, a equipe teve que explicar a receita médica a cada paciente no ato da entrega da medicação, e, portanto, as habilidades de comunicação verbal da equipe tiveram que ser adaptadas aos aspectos culturais de cada paciente ${ }^{6}$.

$\mathrm{Gil}^{7}$ comenta o processo de adoção de elementos socioculturais do exterior por parte das sociedades indígenas na saúde, pela apropriação de conceitos e ferramentas tais como a utilização do conceito de "remédios" da cultura dos "brancos" para substâncias e elementos que os indígenas acreditam terem propriedades curativas. Esse processo pode também ser notado nas comunidades brancas ribeirinhas como as visitadas, onde, por causa da dificuldade de acesso ao tratamento médico disponível nos centros urbanos, a população amazônica usa outros processos curativos, como rezas, partes de animais e produtos botânicos, além de ter suas próprias concepções sobre o processo saúde-doença. O contexto regional no qual essas comunidades estão inseridas e a multiplicidade de fatores culturais, socioeconômicos e geográficos que determinam os hábitos e os comportamentos relacionados ao processo saúde-doença acabam por determinar as práticas em saúde dessas comunidades ribeirinhas. Esse componente deve ser entendido por qualquer equipe de saúde que se propõe a prestar atendimento a essas populações especiais.

\section{CONCLUSÕES}

É de extrema valia que os cursos médicos localizados na Amazônia proporcionem em sua grade curricular atividades em áreas distintas com foco na Medicina Tropical e na realidade local. A atividade em equipe com discentes de diferentes períodos letivos é possível, permitindo a troca de experiências entre eles e a construção do conhecimento mútuo conforme habilidades específicas. Por fim, o contato dos moradores de áreas ribeirinhas com equipes universitárias pode criar uma ponte para um melhor entendimento das necessidades especiais das populações amazônicas típicas e contribuir para uma política de saúde regionalizada de melhor qualidade.

\section{REFERÊNCIAS}

1. Alunos de medicina ficam espremidos em enfermarias em RO. Jornal Nacional. [online] 11 dez. 2012. [acesso em 31 jan 2013]: [cerca de 1 tela]. Disponível em: http:/ /g1.globo. com/jornal-nacional/noticia/2012/12/alunos-de-medicina-ficam-espremidos-em-enfermarias-em-ro.html

2. Dornan T, Bundy C. What can experience add to early medical education? Consensus survey. BMJ. 2004;329(7470):834-9.

3. Escolas médicas do Brasil [homepage]. [acesso em 31 jan. 2013]. Escolas por Estado; [aproximadamente 1 tela]. Disponível em: http:/ / escolasmedicas.com.br/estado.php 
4. Teal CR, Street RL. Critical elements of culturally competent communication in the medical encounter: a review and model. Soc Sci Med. 2009;68(3):533-43.

5. Dornan T, Littlewood S, Margolis SA, Scherpbier A, Spencer J, Ypinazar V. How can experience in clinical and community settings contribute to early medical education? A BEME systematic review. Med Teach. 2006;28(1):3-18.

6. Okoro ON, Odedina FT, Reams RR, Smith WT. Clinical cultural competency and knowledge of health disparities among pharmacy students. Am J Pharm Educ. 2012; 76(3):40

7. Gil LP. Políticas de saúde, pluralidade terapêutica e identidade na Amazônia. Saúde Soc. 2007;16(2):48-60.

\section{CONTRIBUIÇÃO DOS AUTORES}

Todos os autores participaram do atendimento aos ribeirinhos e das discussões sobre a elaboração do artigo.

\section{CONFLITO DE INTERESSES}

Declarou não haver.

\section{ENDEREÇO PARA CORRESPONDÊNCIA}

Mônica da Silva-Nunes

Universidade Federal do Acre, Centro de Ciências da Saúde e Desporto, Medicina

BR 364, Km 04

Distrito industrial - Rio Branco

CEP. 69920-900 Cx. Postal 500 - AC

E-mail: msnunes1@yahoo.com.br 